\title{
A Study on the Law of Cyclical Fluctuation of Carbon Price-Empirical Evidence from EU ETS
}

\author{
Xing Yang1,2, Hanfeng Liao ${ }^{1}$ \\ ${ }^{1}$ School of Economics, Jinan University, Guangzhou, China \\ ${ }^{2}$ School of Economics, Guangzhou College of South China University of Technology, Guangzhou, China \\ Email: liaohanfeng000@163.com
}

How to cite this paper: Yang, $\mathrm{X}$. and Liao, H.F. (2018) A Study on the Law of Cyclical Fluctuation of Carbon Price-Empirical Evidence from EU ETS. Low Carbon Economy, 9, 81-100.

https://doi.org/10.4236/lce.2018.94007

Received: November 22, 2018

Accepted: December 11, 2018

Published: December 14, 2018

Copyright ( 92018 by authors and Scientific Research Publishing Inc. This work is licensed under the Creative Commons Attribution International License (CC BY 4.0).

http://creativecommons.org/licenses/by/4.0/

c) (i) Open Access

\begin{abstract}
Based on the trading data of the Bluenext and the European Climate Exchange (ECX), this paper analyzes the cyclic price fluctuations of the EU carbon emission rights by means of the maximum entropy spectrum and wavelet variance. The results show that: 1 ) there are obvious cyclical price fluctuations in the EU carbon trading market, with the longest cycle being 33 months and the shortest $5.7 ; 2)$ researches on the factors that affect the cyclical price fluctuations of carbon emission rights manifest that power prices (POWER) exert the greatest implication on the prices of carbon emission rights, followed by coal prices (COAL). For every $1 \%$ change in POWER, the price of carbon emission rights changes $10.95 \%$ towards the same direction. For every $1 \%$ change in COAL, the price of carbon emissions changes $9.28 \%$ towards the opposite; 3) research based on variance decomposition demonstrates that electricity prices contribute the most to the changes of the price of carbon emissions, and the variance contribution rate is $13 \%$ at a lag cycle of 30 days.
\end{abstract}

\section{Keywords}

Price of Carbon Emission Rights, Cyclical Fluctuation, Maximum Entropy Spectrum, Wavelet Variance, Influencing Factors

\section{Introduction}

The EU-ETS market has been running for 12 years. The price of carbon emission rights has undergone severe fluctuations in the past 12 years. For example, the EUA spot price once rose to $€ 30 /$ ton, and its bottom price was as low as $€ 0.01 /$ ton. These fluctuations stem from a wide range of factors, such as seasonal factors, cyclical factors, external economic shocks and changes in a country's political systems and policies. There are at least three problems to be considered to 
study the cyclical price fluctuations of carbon emission rights: First, is there a typical cyclical change in the price fluctuation of carbon emission rights? Is such a cycle strict or probabilistic? Second, if there is a cycle, how long is it? How should its authenticity be verified? Third, what are the factors that cause the cyclical fluctuations of carbon market prices, and what are the main factors among them? This paper aims to seek answers to the aforementioned questions through research.

There are few studies specifically focusing on the cyclical price changes of carbon emission rights. Influential studies include: Zhu and Fang [1] tested the volatility of carbon emissions by constructing a dynamic stochastic general equilibrium model including the fluctuation of energy prices, which showed the fluctuations of carbon emissions were obviously pro-cyclical. Liu [2] held that there was an average cycle of 225-day in the second stage of EUA futures price by using the multiplicative variance V/S analysis. Zhu [3] utilized EMD algorithm to decompose the price data of carbon futures of EU ETS from 2005 to 2011 into seven IMF and a residual term. He calculated the average cycle of each sequence by using the number of peaks and troughs of each sequence. He believed the average cycle of the high-frequency component was eight days, while that of the low-frequency component was 96 days. Sartor [4] discovered cyclical fluctuations in EUA prices through the HP filter.

Nevertheless, in the field of other financial assets, research on cyclicity abounds. Liow [5], based on monthly data, used HP filter to analyze the business cycle and stock market cycle of the United States, the United Kingdom and other countries. It was found that there was a long cycle of over eight years and a traditional cycle of 1.5 - 8 years. Fidrmuc [6] employed wavelet spectrum analysis to study the business cycle of China and other G7 countries. It was concluded that there were 23 quarterly cycles in China. Strohsal [7] studied financial cycles of the United States, Britain and Germany by combining the ARMA model with the spectral estimation. It was discovered there were 6.5, 6.6 and 7.6 short cycles and 14.4, 12.7 and 11.7 long cycles in the United States, Britain and Germany, respectively. Golosony [8], based on the BP method, analyzed the cycles and secular trends of metal price fluctuations over the past century. He calculated the maximum and minimum amplitudes of boomcycle and recession cycle, arguing there were five super cycles; Parker [9] used Kalman filter to measure the cycle and amplitude of German hog price fluctuations. The results showed there was a significant fluctuation cycle of four years in the price. Castro [10] used Markov transformation model in his study on measuring the Portuguese stock market cycle from 1989 to 2012. It was proved that there were six bear and bull market alterations in thirteen years. Naccache [11] identified the cycle of oil price change by wavelet analysis and found that the cycle of oil price change was 20 40 years.

Moreover, researches on the driving factors of the carbon price have been popular over the past decade. Deeney et al. [12] used the event study method to 
analyze the price impact, finding that decisions of the European Parliament had influences on the fluctuations of EUA. Ortas [13] applied wavelet correlation graph and cross spectrum to analyze the correlation between the prices of carbon futures and energy commodities such as crude oil at the second stage. It was concluded that there was a positive correlation between the price of carbon emission rights and oil prices (OIL). However, the relationship between the natural gas price (GAS) and the price of carbon emission rights reversed in the high-frequency part. Rickels et al. [14] maintained that the European economy and hydropower supply had significant impacts on the price fluctuations of the EU carbon emission rights at the second stage. By using the BSVAR model and CVAR, Hammoudeh [15] and Aatola [16] found the changes in OIL, COAL, GAS, and POWER could explain short-term fluctuations in the price of carbon dioxide emission rights. Creti et al. [17] found that influences of energy prices on the price of carbon emission rights were inconsistent at the first stage and the second stage through multiple regression analysis. Chevallier [18] found that energy prices, economic activities, unpredictable temperature changes and market events would cause price fluctuations of carbon emissions rights by using the VAR model of the Markov Chain.

\section{Research Method}

\subsection{Maximum Entropy}

As the maximum entropy spectral estimation is superior to the power spectral estimation in resolution, spectral shift and adaptability to short sequence, this paper adopts the maximum entropy spectral analysis to study the fluctuation cycle of carbon prices. The maximum entropy spectrum is:

$$
S_{f}=\frac{P\left(k_{0}\right)}{\left|1-\sum_{k=1}^{k_{0}} B\left(k_{0}, k\right) e^{-2 \pi i k f}\right|^{2}}
$$

In the formula, $f$ is the ordinary frequency and $f=\frac{1}{T}, T$ is the cycle; $i$ is the imaginary number, $P\left(k_{0}\right)$ corresponds to the residual variance of $k_{0}$, $B\left(k_{0}, k\right)$ is the reflection coefficient of order $k_{0}$. The reflection coefficient can be obtained by the Burg algorithm, and the cutoff order $k_{0}$ can be determined by the FPE rule.

The red noise standard spectrum is used to test the significance of the maximum entropy spectrum, which works by constructing $\chi_{v}^{2}$ statistics.

$$
W(f)=\frac{v S(f)}{S_{R}(f)} \sim \chi_{v}^{2}
$$

$v$ is the degree of freedom of the spectral estimation, and $v$ and $S_{R}(f)$ are calculated as follows:

$$
v=\frac{2 n-2 / 3 m}{m}
$$




$$
S_{R}(f)=\overline{S(f)} \frac{1-r^{2}}{1+r^{2}-2 r \cos (2 \pi f)}
$$

In the formula, $\mathrm{n}$ is the length of the sequence, $\mathrm{m}$ is the maximum time delay of the spectral estimation, $\overline{S(f)}$ is the average of the entropy spectral estimation, $r$ is the autocorrelation coefficient of the original sequence of a lagging order, $f$ is the corresponding frequency, and the given significance level is $\alpha=0.05$, $W(f)>\chi_{v}^{2}(1-\alpha)$. The frequency corresponding to the cycle is significant; otherwise, the cycle would not be significant.

\subsection{Wavelet Variance Method}

Wavelet Analysis (WA) was put forward by Morlet in the early 1980s, which is a time-frequency multi-resolution method for studying time sequence. It can clearly reveal the variation cycles hidden in a time sequence, fully reflect the variation trend of a system at different time scales, and estimate the development trend of a system in the future. Concrete steps of determining the cycle of wavelet analysis are as follows: 1) selecting a suitable basic wavelet function; 2) calculating wavelet coefficients and drawing wavelet coefficient map (real part, modulus); 3) drawing the wavelet variance map.

1) Selecting a suitable basic wavelet function

When we transform a time sequence into wavelets, the selection of mother wavelet is very significant. At present, there are many wavelet functions to choose from, such as Mexican hat wavelet, Haar wavelet, Morlet wavelet and Meyer wavelet. Here, Morlet complex wavelet is selected as wavelet basis. Morlet wavelet is a complex one, whose modulus and real parts are two important variables. The magnitude of the modulus stands for the intensity of the characteristic time scale signal, while the real parts represent the distribution and phase information of different characteristic time scale signals in various time.

$$
\psi_{0}(t)=\pi^{-1 / 4} e^{i \omega_{0} t} e^{-t^{2} / 2}
$$

In the formula: $t$ is time, $\omega_{0}$ is dimensionless frequency, when $\omega_{0}=6$, wavelet scale $a$ and Fourier cycle are almost equal $(\lambda=1.03 a)$, and thus scale term and cycle term can substitute each other.

2) Calculating wavelet coefficients and drawing wavelet coefficient map

$$
W_{f}(a, \tau)=\frac{1}{\sqrt{a}} \int_{-\infty}^{+\infty} f(t) \bar{\psi}\left(\frac{t-\tau}{a}\right) \mathrm{d} t, a>0
$$

Formula (6) is the continuous wavelet transform of the function $f(t)$, $W_{f}(a, \tau)$ is the coefficient of the wavelet transform, $\bar{\psi}\left(\frac{t-\tau}{a}\right)$ is the conjugate complex function of $\psi\left(\frac{t-\tau}{a}\right), a$ is called scale factor or stretch factor, $\tau$ is called shift factor.

3) Drawing the wavelet variance map

The square of the absolute value of the coefficients of all wavelet transform is integrated across the entire time domain, i.e., the wavelet variance. The wavelet 
variance is:

$$
\operatorname{Var}(a)=\int_{-\infty}^{+\infty}\left|W_{f}(a, \tau)\right|^{2} \mathrm{~d} \tau
$$

Based on the wavelet variance, the wavelet variance graph is a function of the variance concerning time scale $a$. It reflects the distribution of the fluctuation energy with the scale, and each peak value in the graph corresponds to the significant cycle respectively. When the wavelet variance hits the maximum, the scale of the corresponding wavelet function coincides best with the sequence cycle. It indicates that the cyclical oscillation at this scale is the most dramatic, which is called the main cycle.

The significance of wavelet variance is tested by red noise. The theoretical value of red noise is:

$$
P=\frac{\delta^{2} P_{a} \chi_{v}^{2}}{v}
$$

$\chi_{v}^{2}$ stands for $\chi^{2}$ with a freedom degree $v, \sigma^{2}$ is the variance of the original sequence, $P_{a}$ is the value of red noise at different scales $a$

$$
P_{a}=\frac{1-r^{2}}{1+r^{2}-2 r \cos \left(\frac{2 \pi \delta t}{1.033 a}\right)}
$$

$r$ is the autocorrelation coefficient for the original sequence of lagging order, $\delta t$ is the interval of time sequence.

\section{Existence Test of Cyclical Price Fluctuations of Carbon Emission Rights Sequence}

This chapter adopts the maximum entropy spectral analysis and wavelet variance method to compare the fluctuation cycles of carbon prices, so as to explore the length of such fluctuation cycles. The data used in this paper stem from the EUA spot prices collected by Blue next and European Climate Exchange $(\mathrm{ECX})^{1}$. The data cycle is from Phase II of the EU carbon trading system, ranging from March 2008 to November 2017, totaling 117 months of data. The empirical analysis is conducted by MATLAB7.0.

\subsection{Trend Test and Removal}

\subsubsection{Trend Test}

It is necessary to analyze whether there is a trend before conducting cyclical tests. If there is one, the cyclical test should be carried out after the trend is removed. The trend test is performed by Kendall rank correlation test and run test.

Table 1 shows results of Trend test. The results of Kendall rank correlation test and run test are -8.8233 and -8.8922 , respectively, whose absolute values are above 1.96 at $95 \%$ confidence level; it indicates that there was a trend in the original price sequence, and hence there is a need to conduct cyclical analysis after removing the trend.

${ }^{1}$ Price in Phase II from Bluenext, and price in Phase III from ECX. 
Table 1. Results of Trend test.

\begin{tabular}{ccc}
\hline Method & Kendall rank correlation test & Run test \\
\hline$\mu$ & -8.8233 & -8.8922 \\
$\mu_{\frac{\alpha}{2}}(\alpha=0.05)$ & 1.96 & 1.96 \\
\hline
\end{tabular}

\subsubsection{Trend Removal}

For a sequence with a trend, the H-P filter method is adopted to remove the trend to obtain the cyclical component. The effect of HP filter is as shown in Figure 1.

Figure 1 shows that the trend of the cyclical component after trend removal is basically the same as that of the original price sequence, and yet its cyclicity is more significant than that of the original price sequence.

\subsection{Existence and Cycle Length of Cyclical Fluctuations}

For time sequence with removed trend components, the maximum entropy method and the wavelet variance method are applied to test its cyclical existence and cyclical length.

\subsubsection{Maximum Entropy Spectrum and Cyclical Test}

As the maximum entropy spectral estimation is superior to the power spectral estimation in resolution, spectral shift and adaptability to short sequences, it is adopted to test the cyclicity of the new sequences after their trends are removed. Concrete steps include: 1) centralizing and standardizing the original sequence to obtain a new sequence; 2$)$ working out $B\left(k_{0}, k\right)$ and $P(k)$ by the Burg algorithm; 3 ) determining the optimal order according to the FPE; 4) calculating the maximum entropy according to the optimal order and drawing the maximum entropy spectrum.

The FPE rule, commonly used in the maximum entropy, is used to test the FPE effect within 50 orders, (preferably the minimum order of FPE). The result is as shown in Figure 2.

Figure 2 suggests that with the order increasing, the FPE tends to decrease first and then rise; the FPE value is the smallest at the 15th order, so the order of the maximum entropy spectrum is 15 .

Based on the Burg algorithm, the maximum entropy spectrum is solved when the optimal lag order is 15 . The maximum entropy spectrum is drawn by taking frequency $f$ as the abscissa and logarithmic maximum entropy spectrum $S_{f}$ as the ordinate. The reciprocal of the frequency corresponding to the maximum point is the corresponding cycle. The maximum entropy spectrum is as shown in Figure 3.

In the entropy spectrum of Figure 3, there are several maximum points, but at $95 \%$ confidence level of red noise, only three extremes pass the test; their corresponding frequencies are converted into cycles by $T=\frac{1}{f}$, corresponding 


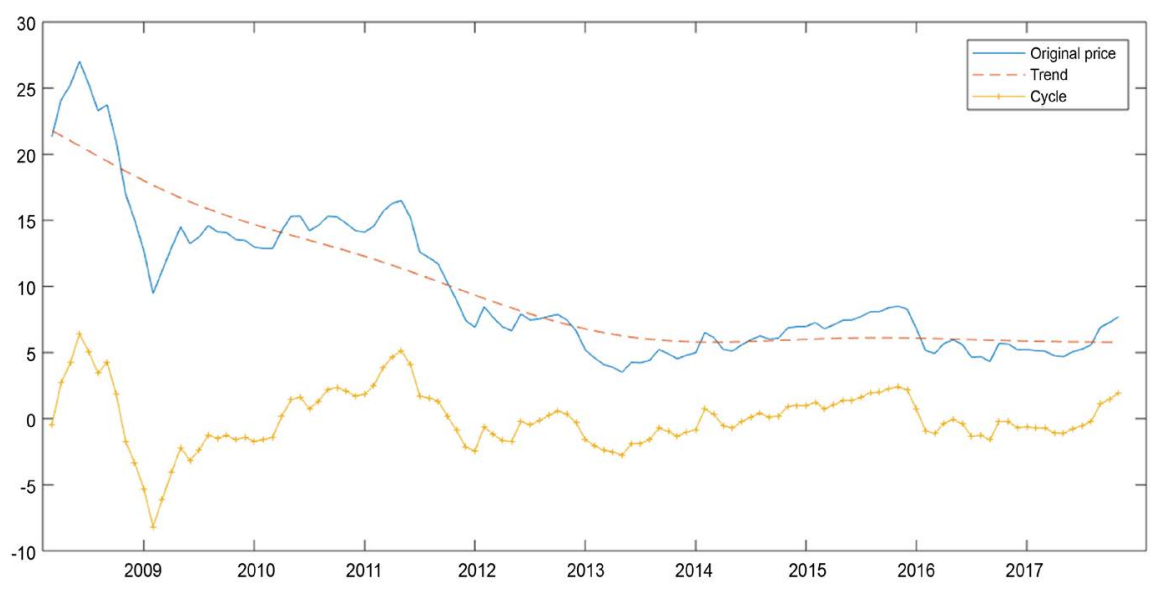

Figure 1. Trend removal chart of HP filter.

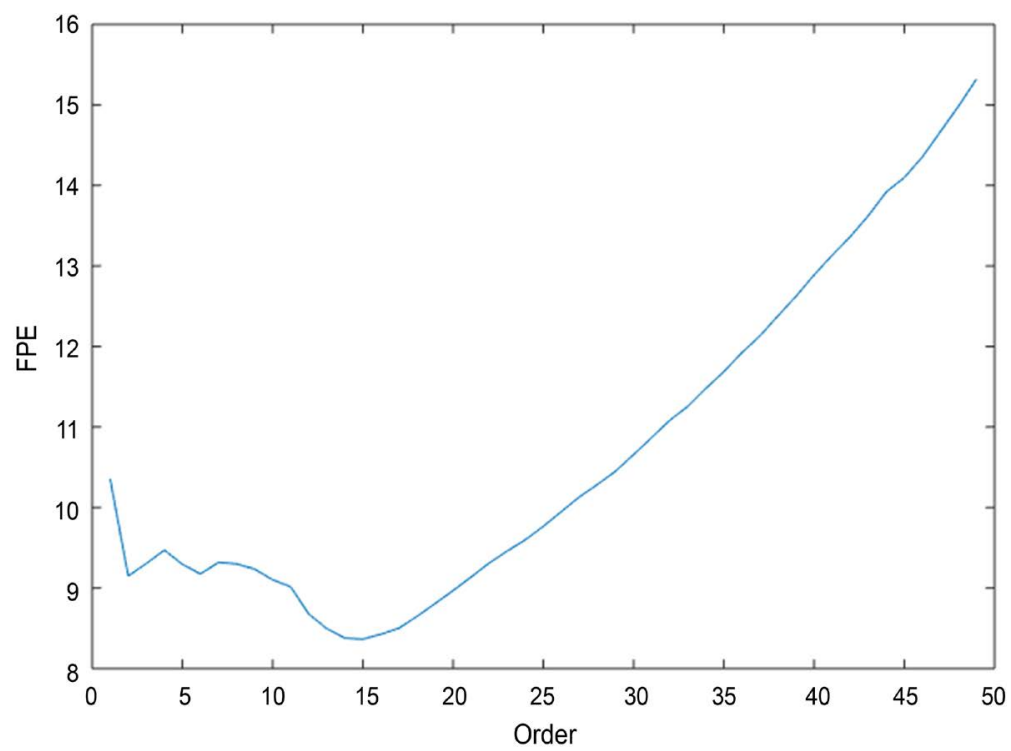

Figure 2. FPE effect within different orders.

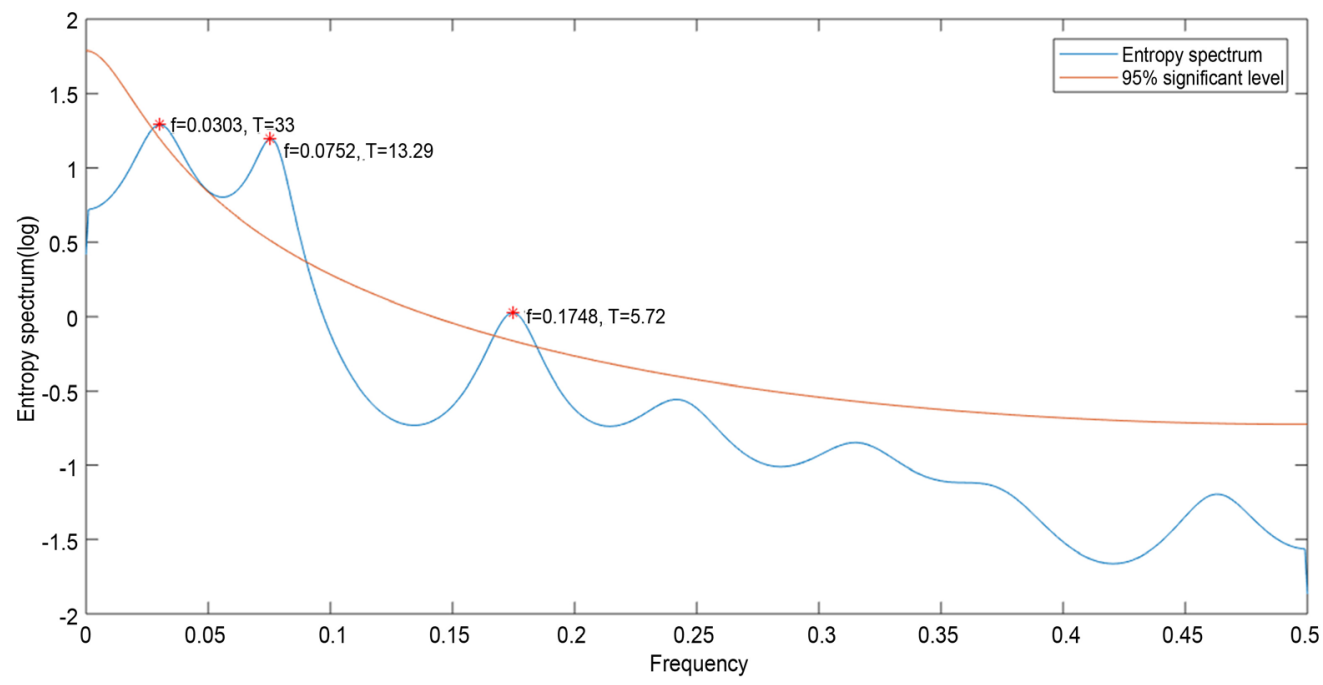

Figure 3. Maximum entropy spectrum and price cycle. 
to $33,13.29$ and 5.72 months. Among them, 33 months correspond to the long cycle, 13 months to the middle cycle, and 5.7 months to the short cycle.

\subsubsection{Wavelet Analysis and Cyclicity Identification}

Morlet wavelet is a complex wavelet, whose modulus and real part are two important variables. The magnitude of the modulus stands for the intensity of the characteristic time scale signals, while the real part represents the distribution and phase information of different characteristic time scale signals in various time. Therefore, this paper adopts Morlet wavelet to study the cycle of carbon prices.

A total of $29 \times 117$ wavelet coefficients are obtained after 112 data are processed by continuous wavelet transform. The isogram for real part and modulus equivalents of wavelet coefficients is as shown in Figure 4.

Figure $4(\mathrm{a})$ is the isogram for the real part of wavelet coefficients, which can reflect the cyclical variation of price sequence at varied time scales and its distribution in the time domain. It can be seen that there are obvious oscillations when the scale is above eight, i.e., when the scales are 10, 16 and 50. It indicates that there is a cycle in the price sequence at these scales. Figure 4 (b) is the isogram for the modulus of wavelet coefficient, which reflects the distribution of the energy density in time domain corresponding to the cycle of variation at different time scales. It can be found that when the scale is above eight, the energy is more concentrated; when the scale is between eight and 16, the energy concentrates before 2014, which indicates that the cycle is strong before 2014; when the scale ranges from 32 to 64 , the energy is greater at each time, but it is more concentrated between 2010 and 2013.

The square of the absolute value of the coefficients of all wavelet transform is integrated in the entire time domain, that is, the wavelet variance. The function graph of variance concerning time scale a is the wavelet variance graph, which

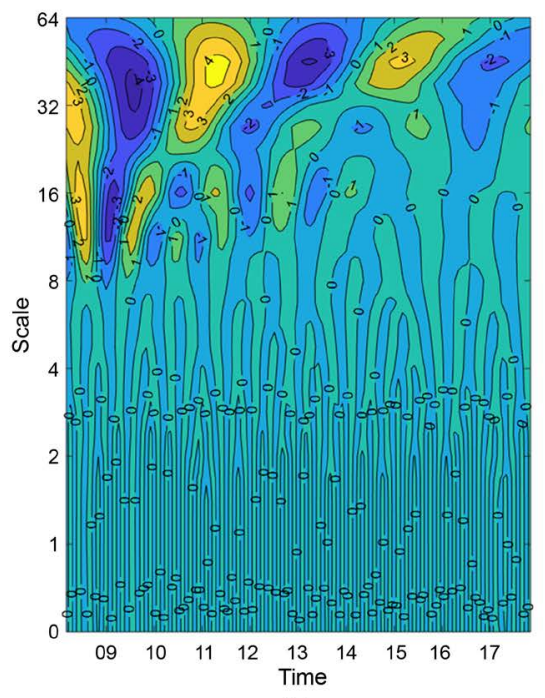

(a)
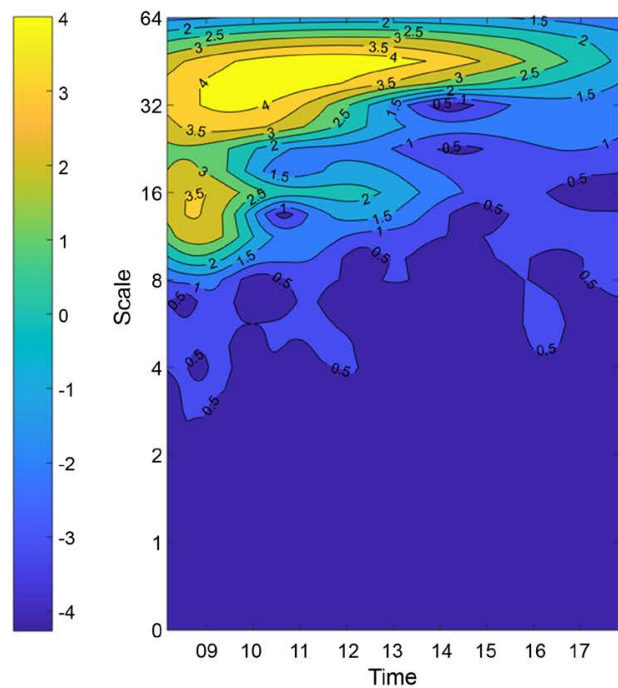

(b)

Figure 4. Isogram for real part and modulus equivalents of wavelet coefficients. 
reflects the distribution of fluctuating energy with the scale. Each peak value in the graph corresponds to the significant cycle respectively. When the wavelet variance hits the maximum, the scale of the corresponding wavelet function coincides best with the sequence cycle. It indicates that the cyclical oscillation at this scale is the most dramatic, which is called the main cycle. Meanwhile, the significance of wavelet variance is tested by red noise.

Figure 5(a) is the original wavelet variance graph, while Figure 5(b) is the logarithm of the ordinate to compensate for the small-scale value of the left graph. Based on the logarithm, it is found that only two extremes, 10 and 16, have passed the significance test, i.e., they represent the two cycles of the sequence, in which 16 months is the first main cycle and ten 10 months is the second.

\subsection{Comparative Analysis of Empirical Results}

By comparing the cycles obtained by dividing peaks and troughs of cyclical components with the cycles obtained by maximum entropy and wavelet variance, the results are as shown in Figure 6 and Table 2.

Figure 6 and Table 2 show that:

1) It is discovered through the maximum entropy that there is a 33-month cycle in price sequence, which is confirmed in the original cyclical component sequence. Since June 2008, there has been three cycles, namely June 2008 to May 2011 (35 months), May 2011 to February 2014 (33 months), and February 2014 to November 2016 (32 months), with an average cycle of 33.3 months, nearly three years. The average cycle length is closest to the Kitchin Cycle, indicating

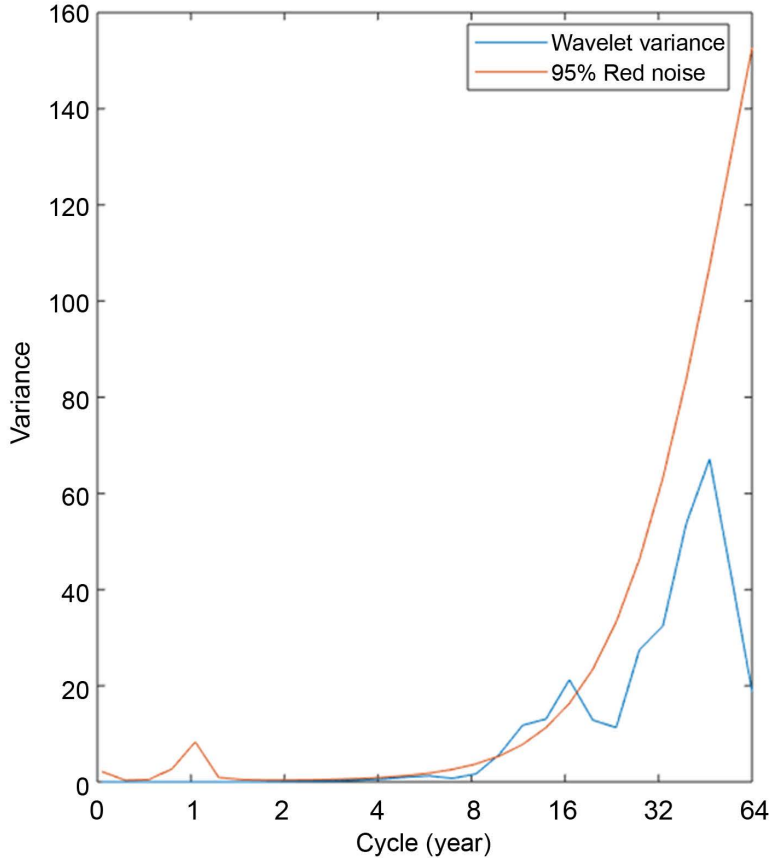

(a)

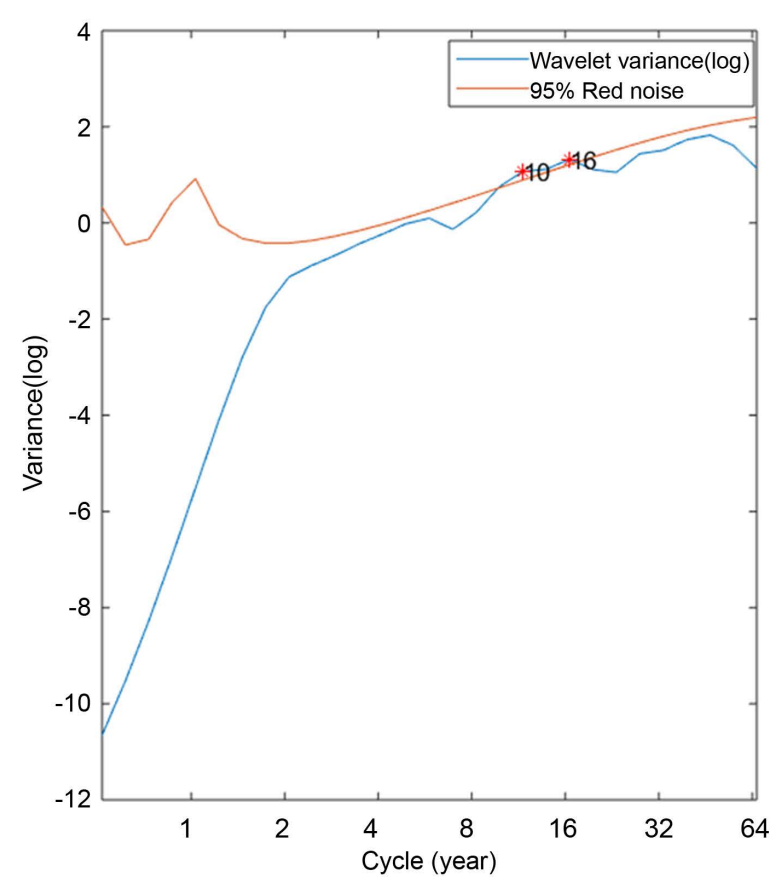

(b)

Figure 5. Wavelet variance graph. 


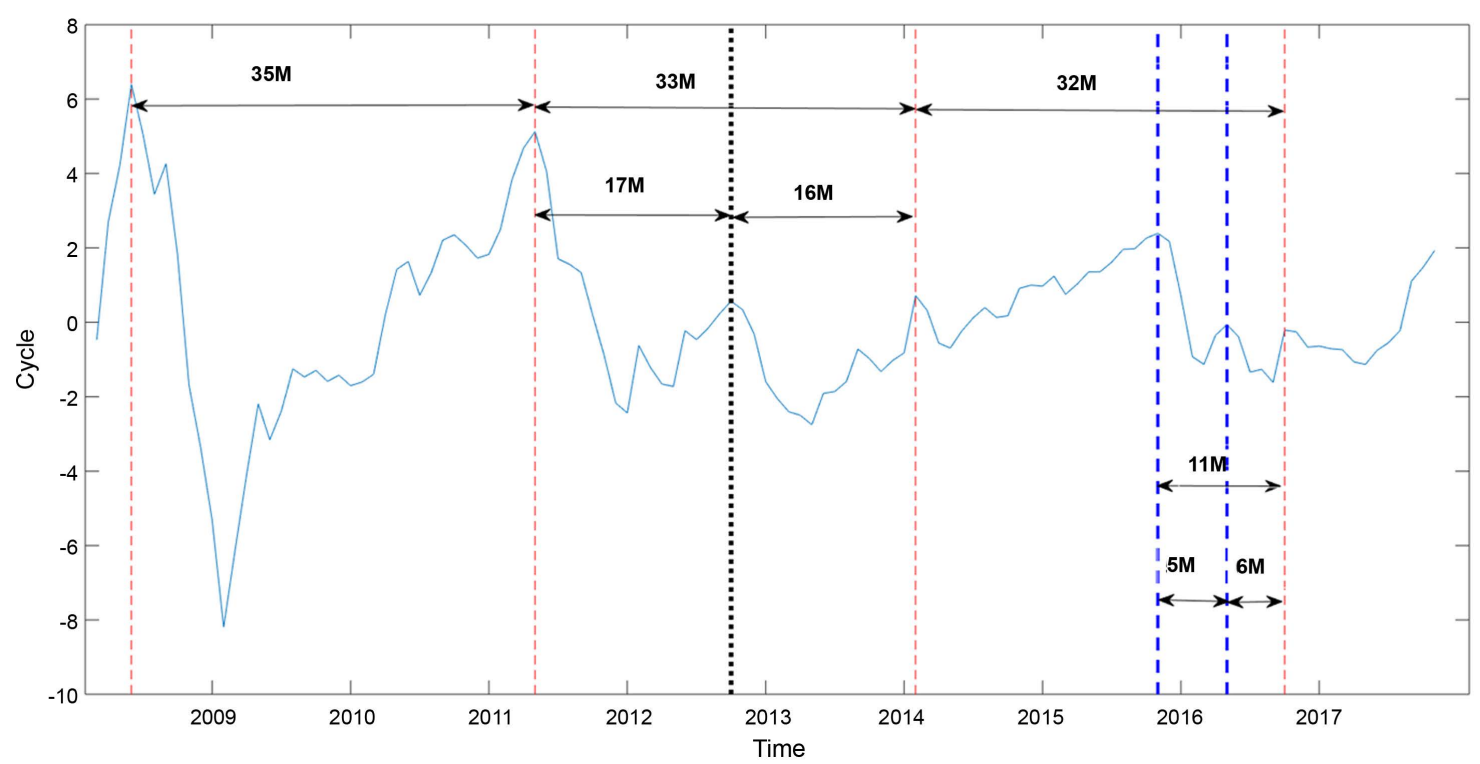

Figure 6. Graph of cyclical component for EUA spot prices.

Table 2. Cyclical table of EUA spot price fluctuation.

\begin{tabular}{cccc}
\hline Time & Sequence Length & Test Cycle \\
\hline $2008.6-2011.5$ & 35 & \\
$2011.5-2014.2$ & 33 & \\
$2014.2-2016.11$ & 32 & 33 \\
Maximum Entropy & Average Cycle & 33.3 & \\
& $2015.12-2016.5$ & 5 & 5.7 \\
$2016.5-2016.11$ & 6 & \\
Average Cycle & 5.5 & 16 \\
2011.5-2012.10 & 17 & \\
2012.10-2014.2 & 16 & 10 \\
\hline Average Cycle & 16.5 & \\
\hline
\end{tabular}

that the cyclical price fluctuations of EU carbon emission rights market generally fall within the Kitchin Cycle, belonging to probability cycle.

2) The first main cycle of wavelet variance is 16 months, which is close to the maximum entropy of 13.2, and has passed the test of red noise. However, only 16.5 -month cycle is found in the actual cycle series, so the 16 months measured by wavelet variance is more accurate. The 16-month cycle is close to half of the 33-month cycle, especially in the cycle from May 2011 to February 2014 (33 months), which can be clearly divided into two intermediate cycles: May 2011 to October 2012 (17 months) and October 2012 to February 2014 (16 months).

At the end of the cycle of from February 2014 to November 2016, the second 
main cycle of about 10 months can be found, which is corresponding to December 2015 to November 2016, a total of 11 months. This cycle is just the sum of the cycle from December 2015 to May 2016 (five months) and May 2016 to November 2016 (six months), which is close to the 5.7 months cycle tested by the maximum entropy. It suggests that the second main cycle of 10 months tested by wavelet and the cycle of 5.7 months that passes the maximum entropy spectrum test are credible.

3) By comparing with the real time sequence, it is found that both the maximum entropy and wavelet variance graph are effective methods to find cycles. Yet, there are some differences between them, and there is a certain margin of error between the calculated cycle and the actual sequence fluctuation. Furthermore, some of the cycles that have passed the significance test are not reflected in the actual sequence graphs, such as the 13.2-month cycle discovered by the maximum entropy.

Overall, the cyclical price fluctuation of carbon emission rights sequence generally belongs to the short cycle fluctuation. The longest cycle is approximately 33 months, which can be divided into two sub-cycles of some 16 months. In addition, there is a shorter cycle of around 10 months in the carbon price sequence, while the 10-month cycleconsists of two cycles of about 5.7 months.

\section{Analysis of the Factors Influencing Cyclical Price Fluctuations of Carbon Emission Rights}

Currently, there are plenty of literatures about the driving factors of carbon prices, but there is no literature to study the causes of cyclical price fluctuations. The factors that affect price fluctuations of carbon emission rights vary, of which direct influences arise from the changes of energy prices, especially the relative prices of fossil energy and clean energy. When the relative prices of clean energy (such as natural gas) and fossil fuels (such as coal) rise, enterprises will choose low-priced coal as fuel and raw materials, in a bid to cut the costs of reducing emissions. Such a rise in carbon emissions increases the demand for and the price of carbon quotas; otherwise, the opposite is true.

Indirect influences stem from the changes in the business cycle. When the economy grows, corporate production activities will increase, so will the needed energy, carbon emissions, corporate demand for quotas, and the prices of quotas. On the contrary, when the economy depresses, corporate production activities and emissions will drop, so will the demands for quotas and the price of carbon emission.

\subsection{Selection of Indicators and Description of Data}

\subsubsection{Selection of Energy Price Indicators}

In order to better reflect the energy prices in Europe, the following four energy price indicators are selected:

1) Coal price (COAL). The DES ARA thermal coal trading price data are selected, which can represent the European coal prices, unit US\$/ton. 
2) Natural gas price (GAS). The natural gas price on Zeebrugge Trading Point, Belgium, is selected as the European natural gas price. Its price represents one of the important ones for European natural gas, which is $€ / M M B t u$.

3) Oil price (OIL). The Brent crude oil price is selected as its contracts of futures are deemed the benchmark price for European crude oil.

4) Power price (POWER). As the German power price is representative in Europe, and thus the daily trading price data of the basic load of German power on the European Energy Exchange are selected, unit €/MWh.

To avoid the influences of different units, the units are all converted into euros, namely $€ 1 / \mathrm{MWh}=€ 8.1414 /$ ton, $€ 1 / \mathrm{MWh}=€(1 / 0.2931) / \mathrm{MMBtu}$ (Tendances Carbone). The prices of coal and natural gas are converted into the same unit.

\subsubsection{Selection of Economic Change Indicators}

The impacts of economic changes on the EUA can be measured by a comprehensive index. The five economic indices, which reflect the changes of business cycles, are selected, while the comprehensive index (ECOI), which represents the business cycles, is obtained by the principal component method.

1) Economic Sentiment Index (ESI). ESI is the leading index to forecast the future economic development and changes. Economic boom refers to the overall economic growth trend, market prosperity, and expediting growth of economic aggregate; economic depression denotes the overall trend of economic decline, sluggish market, stagnant or lucid economic growth.

2) Industrial Production Index (IPI). IPI is a comprehensive index to measure the monthly product quantity of manufacturing, mining, public power and natural gas industry and enterprises. The Index chiefly reflects the output of cyclical industrial equipment, consumer durables and building materials, as well as steel, textiles and other industrial raw materials.

3) Purchasing Manager's Index (PMI) for the manufacturing in the Euro zone. PMI is a composite index, which is composed of five diffusion indices: new order index, production index, employee index, supplier distribution time index and major raw material inventory index.

4) Consumer Confidence Index (CCI). CCI comprehensively reflects and quantifies consumers' expectations of the current economic situation, economic outlooks, and their own incomes. It is a leading index for forecasting economic trends and consumption trends, which is indispensable in monitoring the changes in the economic cycle.

5) Consumer Price Index (CPI). CPI reflects the price changes of consumer goods and services purchased by households. It measures the price changes of a group of representative consumer goods and services in a certain period, and it is a relative index.

For the above five economic indices, the principal component method is adopted to reduce the dimension and obtain the business cycle comprehensive index that affects the price fluctuations of carbon emission rights. The analysis 
results are as shown in Table 3.

Table 3 shows that the first principal component accounts for $68.58 \%$ of the total contribution, suggesting that the first principal component can reflect the overall changes in the five indices. The eigenvalue drops rapidly from the second principal component, and therefore the first principal component is selected as an index to reflect the overall economic changes, recorded as ECOI.

\subsection{Empirical Study}

Based on the above analyses, such six indices as EUA, ECOI, COAL, GAS, OIL and POWER are selected. By using ADF unit root test, co-integration test, VEC model, Granger causality test, variance decomposition and other measurement methods, the dynamic equilibrium relationship and shock response among them are discussed. The above are monthly data, which range from March 2008 to November 2017. In order to eliminate the heteroscedasticity of the data, natural logarithm transformation is carried out.

\subsubsection{Stationarity Test}

ADF test was applied to test the stationarity of the four indices. The results of ADF statistics and $\mathrm{P}$ values are as shown in Table 4.

Table 4 shows that the original sequences are not stationary at $5 \%$ significance level, but the variables become stationary after the first difference, i.e., the sequences are integrated of order 1, I (1) sequence. So, we can conduct the Johansen co-integration test.

\subsubsection{Test of Long-Term Equilibrium Relationship among Variables} In order to explore whether there is a long-term equilibrium relationship among

Table 3. Results of principal component analysis of indices.

\begin{tabular}{|c|c|c|c|c|c|}
\hline & $\begin{array}{c}\text { First principal } \\
\text { component }\end{array}$ & $\begin{array}{l}\text { econd principa } \\
\text { component }\end{array}$ & $\begin{array}{c}\text { Third principal } \\
\text { component }\end{array}$ & $\begin{array}{l}\text { Fourth principal } \\
\text { component }\end{array}$ & $\begin{array}{c}\text { Fifth principal } \\
\text { component }\end{array}$ \\
\hline Eigenvalue & 3.429 & 0.857 & 0.567 & 0.126 & 0.021 \\
\hline Contribution rate & $68.580 \%$ & $17.135 \%$ & $11.344 \%$ & $2.529 \%$ & $0.412 \%$ \\
\hline $\begin{array}{c}\text { Cumulative } \\
\text { Contribution rate }\end{array}$ & $68.580 \%$ & $85.715 \%$ & $97.059 \%$ & $99.588 \%$ & $100.000 \%$ \\
\hline
\end{tabular}

Table 4. ADF stationarity test.

\begin{tabular}{cccccc}
\hline Variable & $\begin{array}{c}\text { ADF value of } \\
\text { original sequence }\end{array}$ & $\begin{array}{c}\text { P value of original } \\
\text { sequence }\end{array}$ & $\begin{array}{c}\text { ADF value of first } \\
\text { difference }\end{array}$ & $\begin{array}{c}\text { P value of first } \\
\text { difference }\end{array}$ & Conclusion \\
\hline LnEUA & -2.283201 & 0.1792 & -8.186274 & 0.0000 & I (1) \\
LnECOI & -2.248668 & 0.1906 & -4.697101 & 0.0002 & I (1) \\
LnCOAL & -2.256970 & 0.1878 & -5.989244 & 0.0000 & I (1) \\
LnGAS & -2.753237 & 0.0683 & -10.00783 & 0.0000 & I (1) \\
LnOIL & -1.415176 & 0.5726 & -7.671850 & 0.0000 & I (1) \\
LnPOWER & -2.831189 & 0.0570 & -12.92583 & 0.0000 & I (1) \\
\hline
\end{tabular}


variables, Johansen co-integration test is conducted for verification. As the optimal lag order of Johansen test is the optimal lag order of VAR model minus 1. Thus, the optimal lag order is determined by VAR model, while in the study the maximum likelihood estimation value (LR) is used for the FPE rule, AIC and SI are adopted to determine the optimal lag order. Due to the different lag orders of each rule or criterion, the FPE statistics determines the optimal lag order is order 2 (see Table 5), and the VAR (2) model is established. All the unit roots of the VAR model are less than 1 , indicating that the model is stable.

The Johansen results are shown in Table 6.

Table 6 shows that the co-integration test rejects the hypothesis that there is no co-integration relationship at 5\% significance level, whose trace statistics and $\mathrm{P}$ values are 105.8613 and 0.0084 ; There is at most a set of co-integration hypotheses with trace statistics and P values of 55.70104 and 0.3901 , which does not reject the null hypothesis. It thus indicates that there is only one co-integration vector among the variables, and that the standardized co-integration equation among them is:

$$
\begin{aligned}
\ln \mathrm{EUA}= & -3.384180 \ln \mathrm{ECOI}-9.282753 \ln \mathrm{COAL}+1.183183 \ln \mathrm{GAS} \\
& +1.455523 \ln \mathrm{OIL}+10.95446 \ln \mathrm{POWER}+28.90384
\end{aligned}
$$

Formula (11) shows that the prices of carbon emission rights have negative correlation with ECOI and COAL, but positive correlation with GAS, OIL and POWER. Specific influences are as follows:

1) If POWER changes $1 \%$, the EUA will change $10.95 \%$ in the same direction;

Table 5. Comparison of different lag orders of VAR models.

\begin{tabular}{ccccc}
\hline Lag orders & LR & FPE & AIC & SC \\
\hline 0 & NA & $1.20 \mathrm{E}-08$ & -1.20923 & -1.06109 \\
1 & 1207.46 & $1.68 \mathrm{E}-13$ & -12.3865 & $11.34949^{\star}$ \\
2 & 67.08294 & $1.63 \mathrm{e}-13^{\star}$ & -12.4248 & -10.4988 \\
3 & 56.2904 & $1.71 \mathrm{E}-13$ & -12.3897 & -9.57485 \\
4 & 52.22125 & $1.83 \mathrm{E}-13$ & -12.3508 & -8.6471 \\
5 & 48.55642 & $1.99 \mathrm{E}-13$ & -12.3128 & -7.72018 \\
6 & 44.06606 & $2.25 \mathrm{E}-13$ & -12.2642 & -6.78277 \\
7 & $57.60296^{*}$ & $2.02 \mathrm{E}-13$ & $-12.47645^{\star}$ & -6.10611 \\
8 & 36.03544 & $2.47 \mathrm{E}-13$ & -12.4165 & -5.15726 \\
\hline
\end{tabular}

Table 6. Results of Johansen co-integration test.

\begin{tabular}{ccccc}
\hline Null hypothesis & Characteristic root & Trace statistics & 5\% critical value & P value \\
\hline No $^{*}$ & 0.353496 & 105.8613 & 95.75366 & 0.0084 \\
Max one group & 0.180593 & 55.70104 & 69.81889 & 0.3901 \\
Max two groups & 0.128690 & 32.79603 & 47.85613 & 0.5681 \\
Max three groups & 0.069335 & 16.95391 & 29.79707 & 0.6435 \\
Max four groups & 0.052287 & 8.690517 & 15.49471 & 0.3948 \\
Max five groups & 0.021629 & 2.514615 & 3.841466 & 0.1128 \\
\hline
\end{tabular}


if POWER rises, power-generating enterprises will raise output, resulting in increased demands for carbon emission rights and higher prices.

2) The EUA is negatively correlated with COAL; if COAL changes $1 \%$, the EUA will change $9.28 \%$ in the opposite direction. GAS and OIL is positively correlated with the prices of carbon emission rights; if GAS changes 1\%, the EUA will change $1.18 \%$ in the same direction; if oil changes $1 \%$, the EUA will change $1.46 \%$ in the same direction.

3) If economic development index changes $1 \%$, the EUA will change $3.38 \%$ in the opposite direction. Such a result is inconsistent with the previous analyses, which may result from the imperfect carbon trading system, asymmetric information in recent years. As a result, the EUA continues to fall, from its highest $€ 27$ to lowest $€ 3.5$, which is contradicts normal economic development. Therefore, there is a negative correlation between the EUA and economic development in the model.

\subsubsection{Short-Term Dynamic Relationship among Variables and the Degree to Which They Deviate from Long-Term Equilibrium}

The long-term equilibrium relationship among the variables is obtained by the VAR model, and yet it cannot reflect the short-term dynamic relationship among variables and the degree of long-term and short-term deviation. As such, a vector error correction model (VEC) is constructed in this paper to explore the long-term equilibrium relationship among variables. The forms of the VEC model are as follows:

$\left[\begin{array}{c}\Delta \ln \mathrm{EUA}_{t} \\ \Delta \ln \mathrm{ECOI}_{t} \\ \Delta \ln \mathrm{COAL}_{t} \\ \Delta \ln \mathrm{GAS}_{t} \\ \Delta \ln \mathrm{OIL}_{t} \\ \Delta \ln \mathrm{POWER}_{t}\end{array}\right]$

$=\left[\begin{array}{cccccc}0.187442 & 0.048973 & 0.095414 & -0.066945 & -0.012337 & -0.006375 \\ 0.179259 & -0.311175 & 0.061325 & -0.113242 & -0.014379 & 0.083229 \\ -0.002644 & 0.294368 & 0.394343 & 0.290139 & 0.294787 & -0.340687 \\ 0.013857 & -0.014737 & 0.010442 & 0.043701 & -0.029295 & -0.009917 \\ 0.068816 & 0.161684 & 0.271744 & 0.029528 & 0.238109 & 0.113644 \\ -0.057214 & -0.05943 & -0.138817 & 0.015562 & -0.147525 & -0.011283\end{array}\right]\left[\begin{array}{c}\Delta \ln \mathrm{EUA}_{t-1} \\ \Delta \ln \mathrm{ECO}_{t-1} \\ \Delta \ln \mathrm{COAL}_{t-1} \\ \Delta \ln \mathrm{GAS}_{t-1} \\ \Delta \ln \mathrm{OIL}_{t-1} \\ \Delta \ln \mathrm{POWER}_{t-1}\end{array}\right]$ $+\left[\begin{array}{c}0.016067 \\ -0.00656 \\ -0.004988 \\ 0.022758 \\ 0.003222 \\ 0.40474\end{array}\right] \mathrm{ECM}_{t-1}+\left[\begin{array}{c}-0.009189 \\ 0.010872 \\ -0.001089 \\ -0.009255 \\ -0.003809 \\ -0.006383\end{array}\right]$

$$
\begin{aligned}
\mathrm{ECM}_{t-1} & =\ln E \mathrm{UA}+3.384180 \ln \mathrm{ECOI}+9.282753 \ln \mathrm{COAL}-1.183183 \ln \mathrm{GAS} \\
& -1.455523 \ln \mathrm{OIL}-10.95446 \ln \mathrm{POWER}-28.90384
\end{aligned}
$$


Formula (12) shows that the parameters of each error correction term are basically significant, and the coefficients of error correction terms in this model are less than zero on the whole when the model reflects the short-term dynamic fluctuation relationship among variables. It thus indicates that the model has the tendency of convergence in the long run, consistent with that of the VEC model.

The changes that reflect the deviation of short-term fluctuation deviating from long-term equilibrium among variables are shown in Figure 7: the long-term equilibrium and stability relationship among variables can be described by a. Figure 7 shows that the zero-mean line of short-term fluctuations deviating from the long-term equilibrium is relatively significant before 2009. It speak value is around $€ 4$, while its valley value is about $€-6$. After 2009 , the short-term fluctuations moderated, with the peak value and valley value hovering around $€ 2$ and $€-3$. However, short-term fluctuations multiplied at the end of 2016 , and the valley value is above $€-4$ at the outset of 2017; at the end of 2017, the peak value is higher than that of the previous peak, and there are signs of continued upward tendency, indicating the intensification of price fluctuations recently.

\subsubsection{Causality among Variables}

The Granger causality test is adopted to test the causality among variables. The Granger causality test requires that variables should be stationary and that there should be co-integration relationship among non-stationary variables. As these two requirements have been met in the above research, the Granger causality test can be used. The results of Granger test are as shown in Table 7.

Table 7 indicates that there is a two-way Granger causality among POWER, COAL and the EUA at $10 \%$ significance level. There is one-way Granger causality among the EUA, economic fluctuation index and OIL: ECOI and OIL are the causes of the EUA's Granger, and yet the EUA is not the cause of the two's Granger; in addition, the Granger test shows that there is no Granger causality between GAS and EUA.

Table 7. Results of Granger causality test.

\begin{tabular}{cccc}
\hline Null hypothesis & F statistics & P value & Conclusion \\
\hline LnECOI isn't the cause of LnEUA's Granger & 2.77897 & 0.0447 & Rejected \\
LnEUA isn't the cause of LnECOI's Granger & 1.36903 & 0.2562 & Accepted \\
LnCOAL isn't the cause of LnEUA's Granger & 3.81336 & 0.0122 & Rejected \\
LnEUA isn't the cause of LnCOAL's Granger & 2.62783 & 0.0540 & Rejected \\
LnGAS isn't the cause of LnEUA's Granger & 0.36646 & 0.7774 & Accepted \\
LnEUA isn't the cause of LnGAS's Granger & 1.96996 & 0.1229 & Accepted \\
LnOIL isn't the cause of LnEUA's Granger & 3.39520 & 0.0206 & Rejected \\
LnEUA isn't the cause of LnOIL's Granger & 0.48566 & 0.6930 & Accepted \\
LnPOWER isn't the cause of LnEUA's Granger & 2.34285 & 0.0772 & Rejected \\
LnEUA is not the cause of LnPOWER's Granger & 3.39597 & 0.0206 & Rejected \\
\hline
\end{tabular}




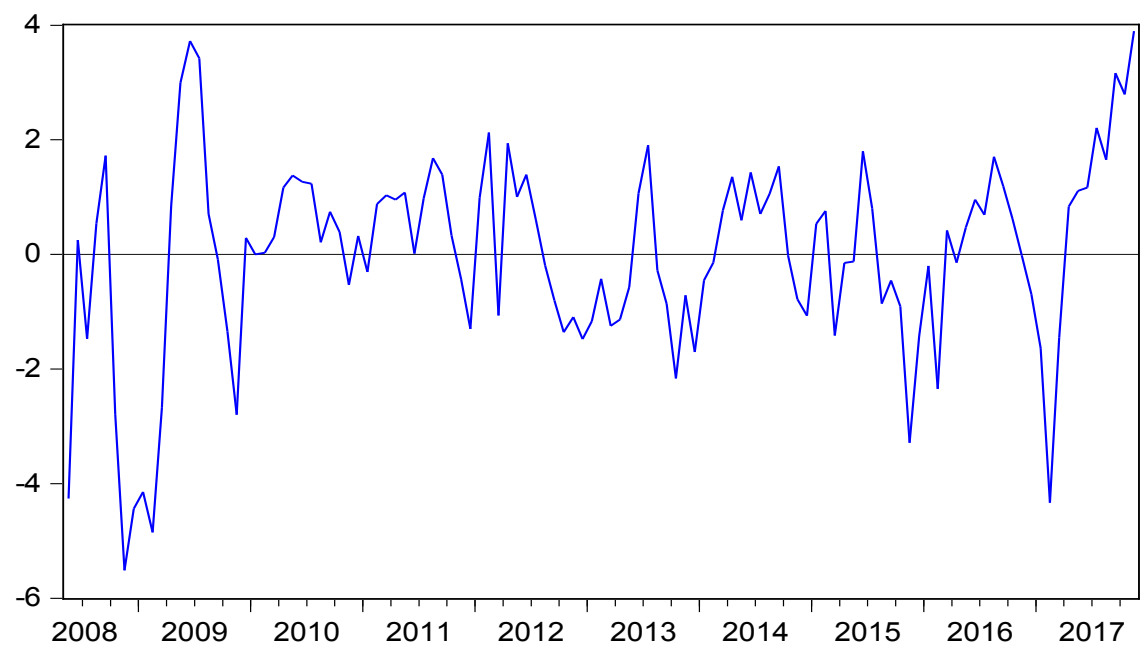

Figure 7. Co-integration graph for Long- and short-term fluctuations.

\subsubsection{Contribution Rates of Various Variables to the EUA fluctuations}

The contribution rate of each variable to the EUA is analyzed by variance decomposition. Variance decomposition can decompose the forecast-period mean squared error of any endogenous variable into the contribution made by the impact of each variable in the system, and then the relative importance of each variable impact is calculated, that is, the contribution rate of the variable. The selected lag length is 30 periods, and the impacts of the variables obtained from Eviews8 on the EUA is shown in Figure 8:

Figure 8 suggests that:

1) POWER has the largest variance contribution rate to the EUA, and its influences on the EUA is ascendant at the beginning; its contribution rate reaches $13 \%$ at the lag period 10 before remaining stable;

2) The variance contribution rate of COAL to EUA starts to rise from period 0 , and reaches $6 \%$ at lag period 10 before remaining stable;

3) The variance contribution rate of GAS to EUA remains zero at the lag period 6 , and then it increases graduall and reaches $5 \%$ at the lag period 30 ;

4) The variance contribution rate of OIL to the EUA remains zero at the lag period 9 , and then it increases gradually and reaches $7 \%$ at the lag period 30 ;

5) The variance contribution rate of ECOI to the EUA is relatively stable and small at each lag period, which is around $1 \%$.

\section{Conclusions}

1) Overall, cyclical price fluctuations of carbon emission rights sequence belong to short cycle fluctuations. The longest period is about 33 months, which can be divided into two sub-cycles of around 16 months. Additionally, there is a shorter cycle of some 10 months in the price of carbon emission rights sequence, which in turn consists of two cycles of about 5.7 months each.

2) The influences of each factor on the price of carbon emission rights are: in the long run, POWER and the relative price of COAL have the greatest impacts 
Percent LNEUA variance due to LNECOI

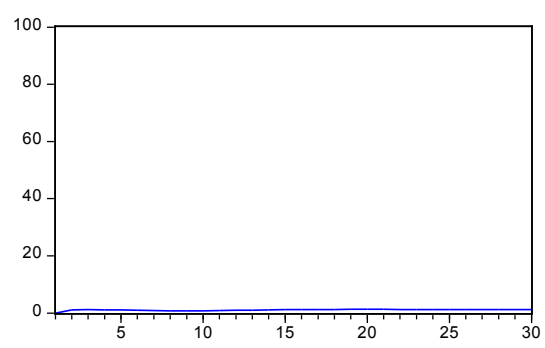

Percent LNEUA variance due to LNOIL

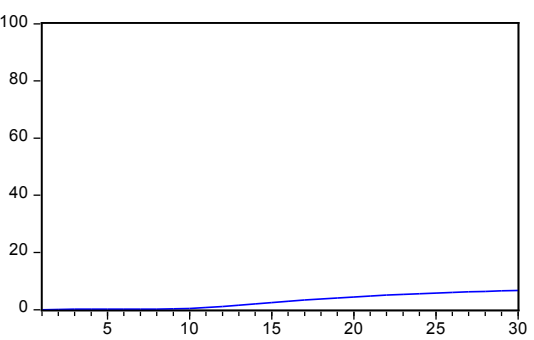

Percent LNEUA variance due to LNCOAL

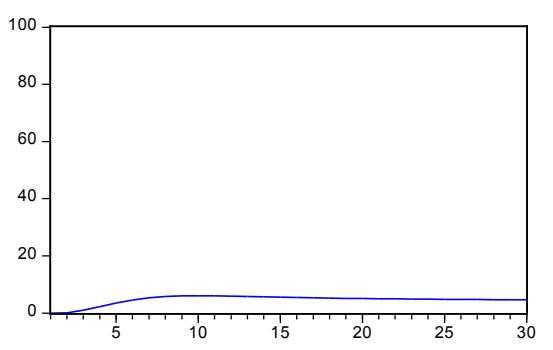

Percent LNEUA variance due to LNPOWER

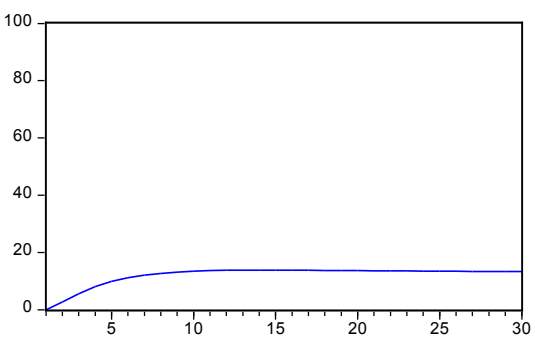

Percent LNEUA variance due to LNGAS

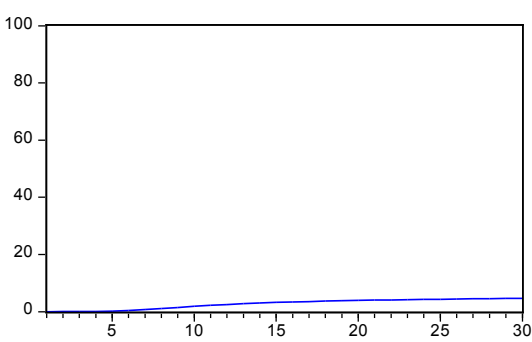

Figure 8. Contribution of each variable to the EUA.

on the price of carbon emission rights. If POWER changes $1 \%$, the price of carbon emissions rights will change $10.95 \%$ in the same direction; if COAL changes $1 \%$, the price of carbon emissions rights will change $9.28 \%$ in the opposite direction. Bessie, an unexpected discovery is that there is a negative correlation between the comprehensive economic index and the price of carbon emission rights, which is inconsistent with the economic reality, and hence further study is needed.

3) The contribution rates of each factor to the price fluctuations of carbon emission rights are as follows: POWER contributes the most to the price of carbon emission rights. The contribution rate of POWER to the price of carbon emission rights is still $13 \%$ at lag period 30 , while that of COAL, OIL and GAS is $6 \%, 7 \%$ and $5 \%$ respectively. Yet, the contribution rate of ECOI is relatively small, approximately $1 \%$ at each lag period, which may arise from the continued economic downturn in Europe in recent years. As a result, the carbon trading market cannot reflect the overall economic development, causing the price of carbon emission rights to negatively correlate with the economic development indicators.

However, there are still some limitations in this paper, such as insufficient data volume, only more than 100 groups, which will affect the accuracy of the cycle. In addition, in terms of influencing factors, this paper only considers the linear relationship between them, but there may be non-linear relationship between them, which will be the focus of later research.

\section{Conflicts of Interest}

The authors declare no conflicts of interest regarding the publication of this paper. 


\section{References}

[1] Zhu, Z.M. and Fan, P. (2015) Study on the Dynamic Impact of Energy Price and Carbon Emission: An Empirical Analysis Based on DSGE Model. Price: Theory \& Practice, 5, 54-56.

[2] Liu, J. (2015) Research on Fractal Feature of European Carbon Market. North China University of Technology.

[3] Zhu, B.Z. and Wang, P. (2012) Multi-Scale Analysis of Carbon Market Price Influencing Factors Based on EMD. Economics Information, 6, 92-97.

[4] Sartor, O. (2012) The EU ETS Carbon Price: To Intervene, or Not to Intervene. Climate Brief, 12, 1-8.

[5] Liow, K.H. (2016) Linkages between Cross-Country Business Cycles, Cross-Country Stock Market Cycles and Cross-Country Real Estate Market Cycles: Evidence from G7. Journal of European Real Estate Research, 9, 123-146. https://doi.org/10.1108/JERER-05-2015-0024

[6] Fidrmuc, J., Korhonen, I. and Poměnková, J. (2014) Wavelet Spectrum Analysis of Business Cycles of China and G7 Countries. Applied Economics Letters, 21, 1309-1313. https://doi.org/10.1080/13504851.2014.920468

[7] Strohsal, T., Proano, C. and Wolters, J. (2015) Characterizing the Financial Cycle: Evidence from a Frequency Domain Analysis. Sfb Discussion Papers, 2015. https://ssrn.com/abstract=2797045

[8] Golosnoy, V. and Rossen, A. (2014) Modeling Dynamics of Metal Price Series via State Space Approach with Two Common Factors. Empirical Economics, 54, 1477-1501. https://doi.org/10.1007/s00181-017-1267-9

[9] Parker, P.S. and Shonkwiler, J.S. (2014) On the Centenary of the German Hog Cycle: New Findings. European Review of Agricultural Economics, 41, 47-61. https://doi.org/10.1093/erae/jbt017

[10] Castro, V. (2013) The Portuguese Stock Market Cycle. Oecd Journal Journal of Business Cycle Measurement \& Analysis, 2013, 1-23. https://doi.org/10.1787/19952899

[11] Naccache, T. (2011) Oil Price Cycles and Wavelets. Energy Economics, 2, 338-352. https://doi.org/10.1016/j.eneco.2010.12.001

[12] Deeney, P., Cummins, M., Dowling, M.M. and Smeaton, A.F. (2016) Influences from the European Parliament on EU Emissions Prices. Energy Policy, 88, 561-572. https://doi.org/10.1016/j.enpol.2015.06.026

[13] Ortas, E. and Álvarez, I. (2016) The Efficacy of the European Union Emissions Trading Scheme: Depicting the Co-Movement of Carbon Assets and Energy Commodities through Wavelet Decomposition. Journal of Cleaner Production, 116, 40-49. https://doi.org/10.1016/j.jclepro.2015.12.112

[14] Rickels, W., Görlich, D. and Peterson, S. (2014) Explaining European Emission Allowance Price Dynamics: Evidence from Phase II. German Economic Review, 16, 181-202. https://doi.org/10.1111/geer.12045

[15] Hammoudeh, S., Nguyen, D.K. and Sousa, R.M. (2014) What Explain the Short-Term Dynamics of the Prices of $\mathrm{CO}_{2}$ Emissions? Energy Economics, 46, 122-135. https://doi.org/10.1016/j.eneco.2014.07.020

[16] Aatola, P., Ollikainen, M. and Toppinen, A. (2013) Impact of the Carbon Price on the Integrating European Electricity Market. Energy Policy, 61, 1236-1251. https://doi.org/10.1016/j.enpol.2013.06.036 
[17] Creti, A., Jouvet, P.A. and Mignon, V. (2012) Carbon Price Drivers: Phase I versus Phase II Equilibrium? Energy Economic, 34, 327-334. https://doi.org/10.1016/j.eneco.2011.11.001

[18] Chevallier, J. (2011) A Model of Carbon Price Interactions with Macroeconomic and Energy Dynamics. Energy Economics, 33, 1295-1312.

https://doi.org/10.1016/j.eneco.2011.07.012 